\title{
Fabrication of complete denture by stereolithography-based 3D printing: a case report
}

\author{
Yina Yun ${ }^{1}$, Minhyuk Park ${ }^{2}$, Sangwon Park ${ }^{3}$, Chan Park ${ }^{4 \star}$, Woohyung Jang ${ }^{5 *}$, and Seon-Ki Lee ${ }^{6}$ \\ ${ }^{1}$ Resident, Department of Prosthodontics, School of Dentistry, Chonnam National University, Gwangju, Republic of Korea \\ ${ }^{2}$ Doctor's Degree, Department of Prosthodontics, Smile Dental Clinic, Gwangju, Republic of Korea \\ ${ }^{3}$ Professor, Department of Prosthodontics, School of Dentistry, Chonnam National University, Gwangju, Republic of Korea \\ ${ }^{4}$ Assistant Professor, Department of Prosthodontics, School of Dentistry, Chonnam National University, Gwangju, Republic of Korea \\ ${ }^{5}$ Fellow, Department of Prosthodontics, School of Dentistry, Chonnam National University, Gwangju, Republic of Korea \\ ${ }^{6}$ Assistant Professor, Department of Prosthodontics, Daejeon Dental Hospital, Wonkwang University, Daejeon, Republic of Korea
}

The conventional complete denture has disadvantages such as multiple visits to the dental clinic, including definitive impression and intermaxillary relationship records after taking preliminary impressions and making individual trays and reduced adaptation of the denture base due to the shrinkage of the heat-cured resin. The MAGIC Denture system (Cozahn, Seoul, Korea) requires only a few visits because of intermaxillary relationship records and definitive impression at the first visit and has reduced shrinkage after additive manufacturing of 3D printing. In this case, a 3D-printed denture by MAGIC Denture of Cozahn was manufactured, which required a minimum number of visits for a patient who had difficulty in treatment due to poor cooperation and intended to determine the clinical usefulness. The patient was satisfied with the functional and aesthetic aspects after the final denture was delivered.

Key Words: Complete denture; Resin; 3D printing

(c) This is an open-access article distributed under the terms of the Creative Commons Attribution Non-Commercial License (http://creativecommons.org/licenses/by-nc/4.0) which permits unrestricted noncommercial use, distribution, and reproduction in any medium, provided the original work is properly cited.

\section{Introduction}

의학과 치의학 분야에서 3D 프린팅의 활용은 2010년대부 터 급격히 증가하여 적층제조(additive manufacturing) 방식 에 의해 복잡한 구조의 재현이 가능하며 환자 개인의 맞춤형 의 료 장비 및 모형의 제공이 가능하게 되었다[1]. 최근 3차원 의치 제작 프로그램을 활용하여 3D 프린팅한 의치를 제작하는 코잔 (Cozahn, Seoul, Korea)의 MAGIC Denture는 최소한의 내원
으로 총의치의 제작을 가능하게 하였다. 전통적인 총의치의 제 작은 예비인상 채득 후 진단모형에서 개인트레이를 제작, 최종 인상 채득 및 모형 제작, 악간관계 기록 채득, 인공치아의 배열, 레진의 전입 및 온성, 의치의 연마, 최종 의치의 장착 등을 거쳐 내원 횟수가 증가하고 비용이 증가되는 단점이 있었다[2]. 제조 사의 지시에 따르면 코잔의 MAGIC Denture는 4가지의 플라스 틱 트레이를 기공용 버로 조정한 후 첫 내원 당일 인상채득이 가 능하며 인상채득한 트레이를 조심스럽게 분리한 후 다시 구강

Received July 21, 2021; Revised September 30, 2021; Accepted October 15, 2021

*Co-Corresponding author: Chan Park, Department of Prosthodontics, School of Dentistry, Chonnam National University, 33 Yongbong-ro, Buk-gu, Gwangju 61186, Republic of Korea.

Tel: +82-62-530-5638, Fax: +82-62-530-5639, E-mail: upgradepc@hanmail.net

*Co-Corresponding author: Woohyung Jang, Department of Prosthodontics, School of Dentistry, Chonnam National University, 33 Yongbongro, Buk-gu, Gwangju 61186, Republic of Korea.

Tel: +82-62-530-5638, Fax: +82-62-530-5639, E-mail: awj568@naver.com

Copyright ( 2021, Oral Biology Research Institute 
내에 삽입하여 악간관계를 기록할 수 있다. Lip ruler를 이용하 여 상악 전치부의 길이를 결정하고, jaw gauge를 통해 수직고 경을 결정하며 가상의 치조제를 생성하는 software를 통해 치 아를 배열한다. 광경화성 Stereolithography apparatus 방식의 $3 \mathrm{D}$ 프린터를 이용해 시적의치를 제작하여 입술 지지도, 교합평 면, 수직고경 등을 평가할 수 있기 때문에 필요 시 내면에 wash impression 또는 교합조정 후 이를 반영한 완성도 있는 최종 의 치를 제작할 수 있다. $3 \mathrm{D}$ 프린팅의 적층제조는 디지털 파일 이 미지를 불러와 광경화성 수지에 빛을 조사하여 재료를 연속적 으로 층(layer)을 쌓아 올리는 방식을 말한다. 복잡한 형태의 제 작이 가능하고 정보가 저장되기 때문에 기존 데이터의 재사용 이 용이하다[3]. 코잔의 MAGIC Denture는 첫 내원일에 최종인 상 채득과 악간관계를 기록하기 때문에 최소 두 번만의 방문으 로 의치 제작이 가능하며 전통적인 의치 제작의 기공 시 발생하 는 열중합 레진의 중합수축 오차가 감소하여 내면의 조직 적합 도가 향상된 정확한 의치의 제작이 가능하다. 완성된 의치의 데 이터는 저장되기 때문에 분실이나 파절 시에도 빠른 의치의 제 작이 가능하다[4]. 본 증례는 주기적인 내원이 어려워 빠른 총의 치 제작이 필요한 환자에서 코잔의 MAGIC Denture system으 로 $3 \mathrm{D}$ 프린팅한 의치를 제작하여 빠르고 정확한 의치를 제작하 였으며 심미적, 기능적으로 환자가 만족하였기에 보고하는 바 이다.

\section{Case Description}

본 환자는 61세 남자 환자로 이가 흔들려서 뽑고 위, 아래 전 체 틀니를 만들고 싶다는 주소로 본원에 내원하였다. 임상검사 상 잔존치근과 심한 우식이 관찰되었고 전반적으로 중등도에 서 심한 치주염이 관찰되었다. 특별한 의과적 병력은 없었으며 경제적인 문제가 있어 예후가 불량한 치아들을 모두 발거하고 상악과 하악의 총의치를 계획하였다(Fig. 1, 2). 이전에 치과치 료를 시도하였으나 장기적인 치료 진행에 협조도가 낮아 치료 진행에 실패하였다는 보호자의 진술과 연고지 문제를 고려하 여 내원 횟수를 최소화한 빠른 의치 제작을 위해 코잔(Cozahn, Seoul, Korea)의 MAGIC Denture를 이용한 3D 프린팅 의치를 제작하기로 하였다. $3 \mathrm{D}$ 프린팅 의치에 대해 환자에게 설명하였

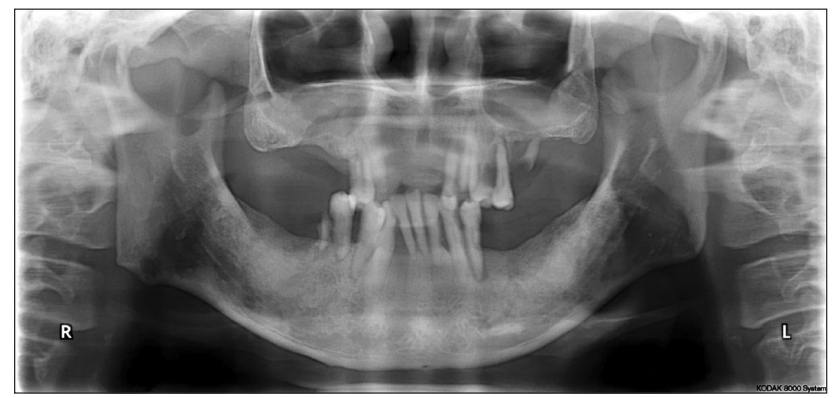

Fig. 1. Initial panoramic radiograph.
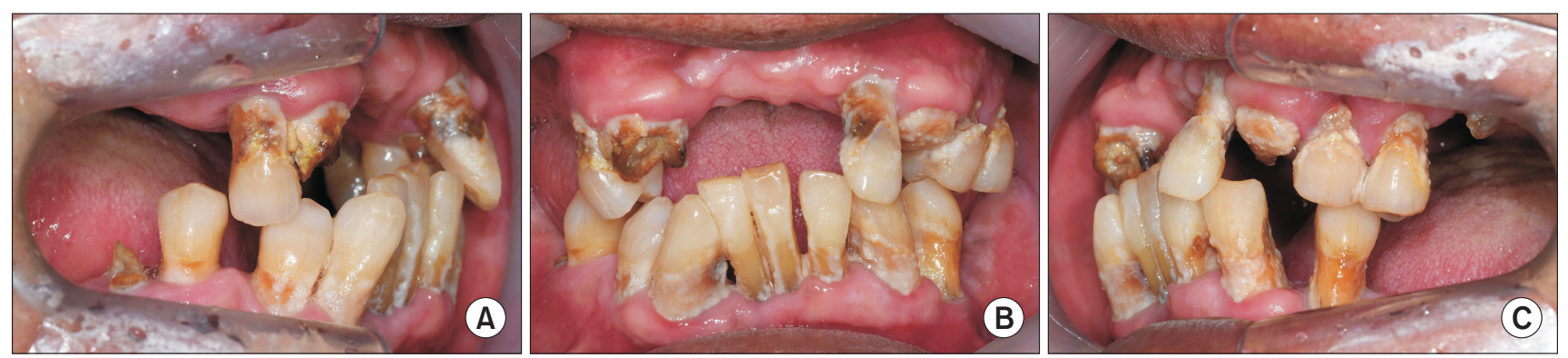

Fig. 2. Initial intraoral photographs. (A) Right view. (B) Frontal view. (C) Left view.
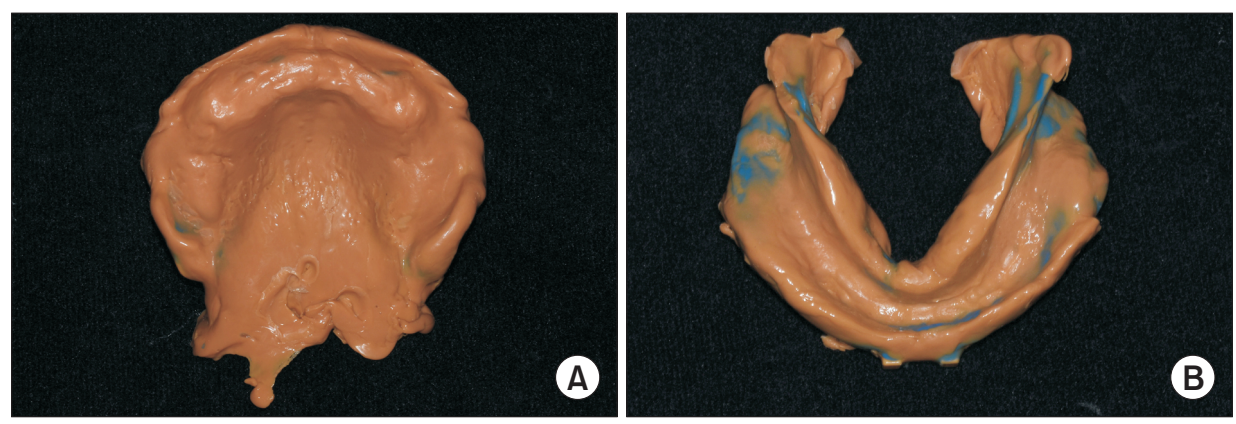

Fig. 3. (A) Maxillary definitive impression. (B) Mandibular definitive impression. 
으며 서면 동의를 받아 진행하였다. 전악 발거 후 임시 총의치를 두 달간 사용 후 최종 의치 제작을 진행하였다.

코잔에서 제공하는 4 가지 사이즈의 트레이 중 상악과 하악에 시적하여 치조제에서 최소 $3 \mathrm{~mm}$ 의 공간이 존재하는 medium 사이즈의 트레이를 선택하였다. 트레이는 상악의 진동선과 하 악의 협붕과 구후융기를 덮도록 했다. 트레이의 변연 길이 및 내 면을 체크하기 위해 Fit checker (Fit Checker Advanced; GC, Tokyo, Japan)를 사용하여 트레이의 변연이 드러난 부위를 조 정 시행하였다. 상악 트레이에 흐름성이 약한 폴리실록산 인상 재(Virtual heavy body; Ivoclar Vivadent AG, Schaan, Liechtenstein)를 담고 통상적인 근육운동을 통해 변연을 형성하여 1차 인상 후 저점도의 라이트 바디 인상재(Virtual light body, Ivoclar Vivadent AG)를 이용하여 정밀한 wash impression을 채득하였다. 1차 인상 후에 노출된 트레이 변연은 추가적으로 덴쳐 버(bur)를 이용해 삭제를 시행하였다. 전술한 방법과 마찬 가지로 하악은 여를 좌우로 움직여서 설측을 형성하고 1차와 2 차 인상채득을 완료하였다(Fig. 3). 인상채득한 트레이의 앞쪽과 뒤쪽 경계 부위를 수술용 \#15 블레이드로 조심스럽게 자른 후 분리시키고 상, 하악 인상체의 전방부를 구강내에 위치시켜 악 간관계 채득에 활용하기로 하였다. 바이트 인상재를 위한 공간 을 확보하기 위해 트레이 윗면의 과도한 인상재를 제거하였다. 기존 임시 의치에 잘 적응하였기에 임시 의치의 수직고경을 최 종의치에 반영하였다. 임시 의치 장착 시 자유공극이 관찰되었 고 Willis 안모계측법과 발음 및 심미 등의 평가에서 문제점을 발견하지 못하였다. 구강 내에 임시 의치를 장착 후 코잔에서 제 공하는 jaw gauge를 이용하여 턱밑부터 코 밑 부분까지의 거리 를 측정하여 임시 의치의 수직고경을 기록하였다(Fig. 4A). 이 후 코잔에서 제공하는 lip ruler로 절치유두에서 상순의 하방선 까지의 거리를 측정하여 상악 전치부 인공치 배열에 참고하였 다(Fig. 4B). 하악 트레이에 묘기침이 딸깍 소리가 날 때까지 꽂 아 완전히 고정하고 기존 임시 의치를 참고하여 나사 형태의 묘 기침을 돌려서 길이를 조정하여 수직고경을 결정하였다. 인상 을 채득한 상악 트레이에 코잔에서 제공하는 EZ-tracer를 부
착하고 상, 하악 트레이를 구강 내에 위치시킨 후 하악을 전후 방, 좌우측으로 운동시켜 운동경로를 기록하였다. 중심위를 채 득한 후 상, 하악 트레이 사이 공간에 교합인기재(Regisil Rigid; Dentsply, Konstanz, Germany)로 악간관계를 채득하였다 (Fig. 5). 인상체와 악간관계 정보를 코잔의 MADIG Denture 기 공소에 의뢰하였다. 기공소에서 스캐너(E1 scanner; 3 Shape, Copenhagen, Denmark)와 스캔 소프트웨어(ScanIt Manager; 3 Shape)를 이용해 상, 하악 인상체를 스캔하고 Standard Tessellation Language 파일로 변환하였다. DENTCA CAD/CAM denture (DENTCA, Torrance, CA, USA)의 인터넷 사이트에 서 해당 파일을 불러들인 후 DENTCA Proprietary Software (DENTCA)를 이용해 상악은 incisive papilla와 hamular notch, 하악은 retromolar pad를 기준으로 가상의 치조제와 교합관계 를 형성한 후 양측성 균형교합을 부여하여 가상의 인공치 배열 을 완성하였다(Fig. 6). 본 증례에서는 안모와 교합관계의 확인 을 위해 시적의치 제작을 의뢰하였고 기공소에서 DENTA Zenith 3D Printer and Printing Software (DENTCA)를 이용해
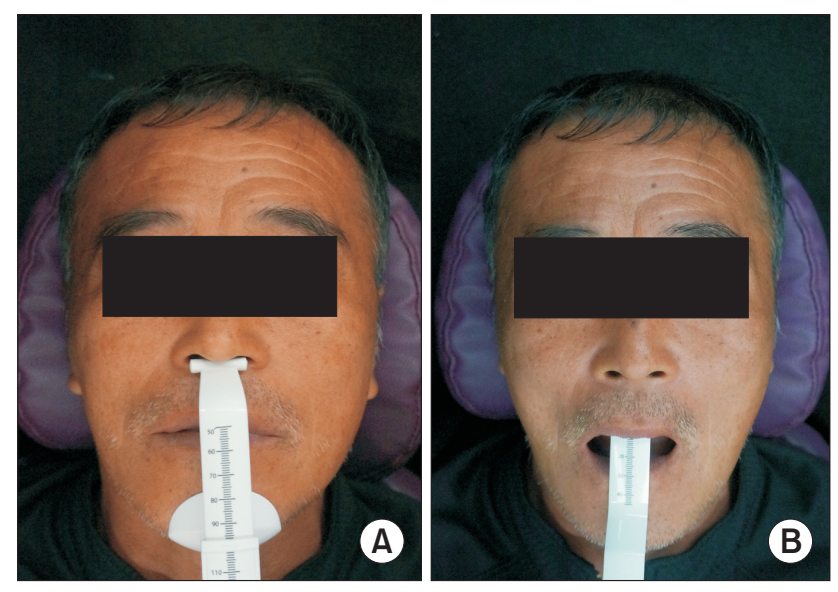

Fig. 4. (A) Jaw gauge to determine vertical dimension referring to the temporary dentures. (B) Lip ruler to measure the length from maxillary anterior labial vestibule to border of upper lip.
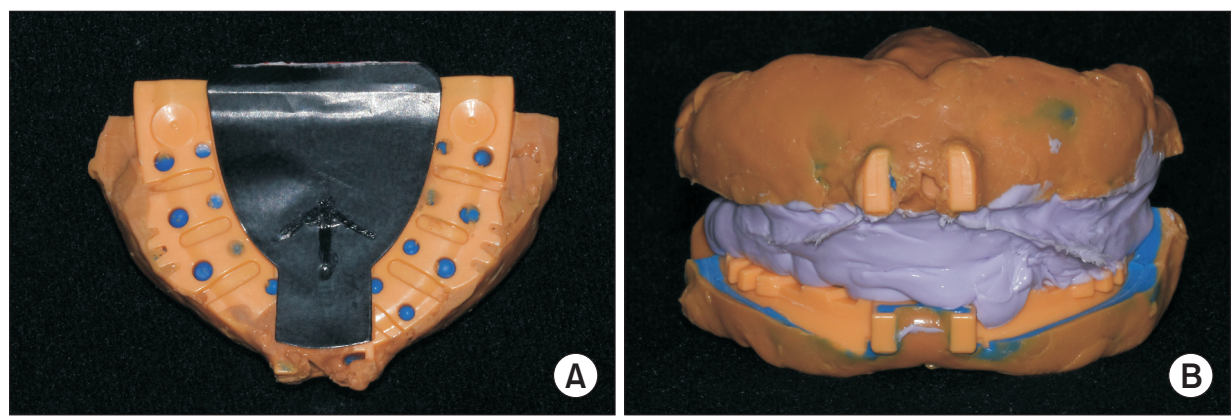

Fig. 5. (A) Gothic arch tracing. (B) Vertical \& horizontal jaw relation record. 

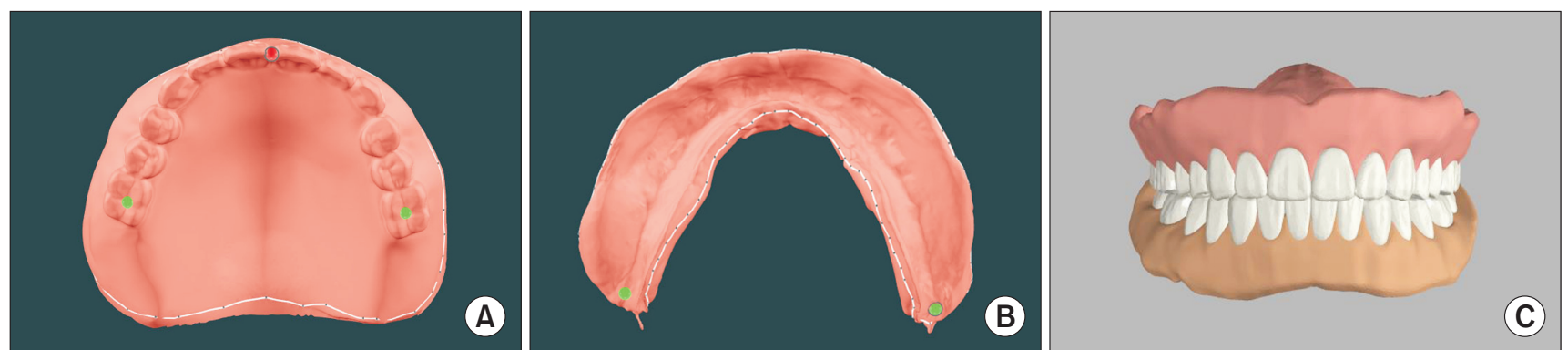

Fig. 6. (A) Maxillary anatomical landmark for occlusal plane. (B) Mandibular anatomical landmark for occlusal plane. (C) Final denture design on the CAD software (DENTCA, Torrance, CA, USA).
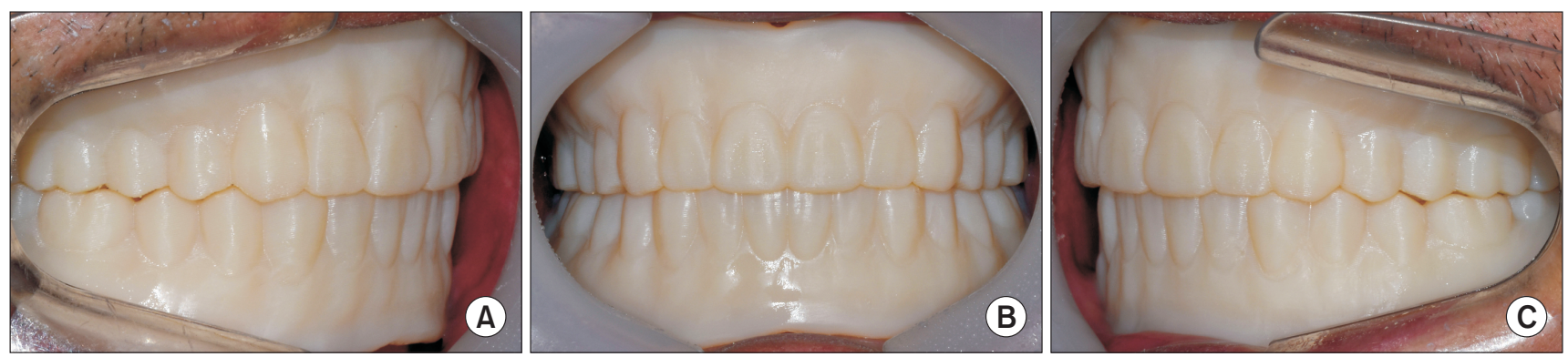

Fig. 7. Trial denture placement. (A) Right view. (B) Frontal view. (C) Left view.
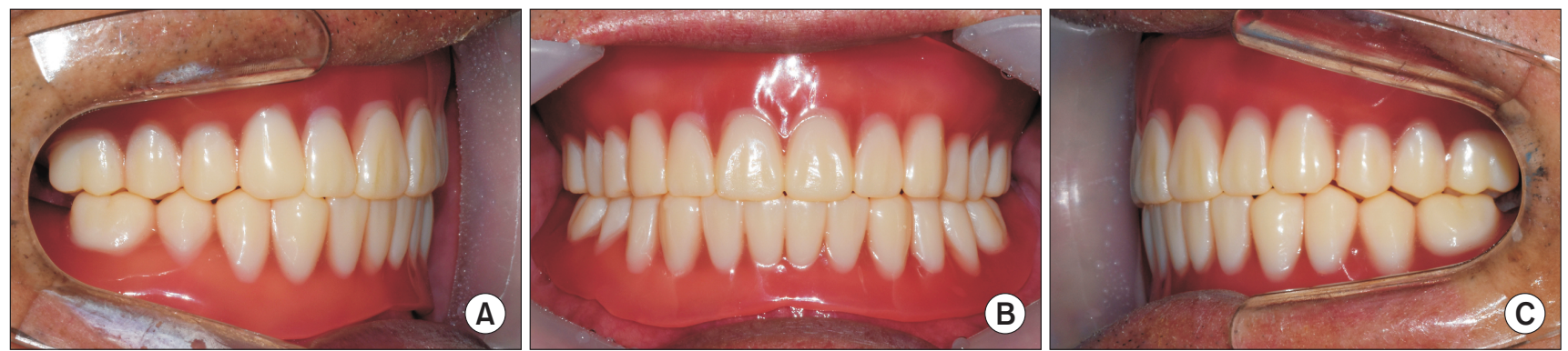

Fig. 8. Fabrication of the 3D-printed definitive dentures. (A) Right view. (B) Frontal view. (C) Left view.

\section{시적의치가 프린팅되었다.}

구강 내에서 시적 의치 장착 후 정중선, 교합평면, 인공치아 배열, 수직고경, 입술 지지도, 내면 적합도, 발음, 연하 등을 평 가하였다(Fig. 7). 상악 치아의 정중선은 안면의 정준선과 일치 하였으며 교합평면은 전두면에서 환자의 동공을 이은 선과 평 행하고 시상면에서 비익이주선과 평행하였다. 전반적으로 양 호한 교합을 보이나 양측성 균형교합을 부여하기 위해 교합조 정을 시행하였다. 내면 적합도가 떨어져서 알루왁스(Aluwax; Aluwax Dental Products, Allendale, MI, USA)로 중심위를 채득한 후 내면을 균등하게 $2 \mathrm{~mm}$ 를 삭제하고 실리콘 인상재 (Exadenture; GC)를 이용하여 폐구인상법으로 wash impresSion 채득하였다. 기공소에 수정사항을 반영한 시적 의치를 전
달하고 인공치아 색상은 A3, 치은색상은 original pink로 선택 한 후 최종 의치 제작을 의뢰하였다. 전술한 과정대로 기공소에 서 시적의치 정보를 이용해 가상의 의치를 디자인한 후 의치사 용 레진(DENTCA Denture Base II, DENTCA)과 인공치용 레 진(DENTCA Denture Teeth, DENTCA)을 이용하여 의치상, 전 치부, 양쪽 구치부 인공치를 각각 따로 프린팅 한 후 의치상 레 진으로 이장하여 광경화를 이용해 인공치와 의치상의 접착을 시행하였다. 의치는 연마 후 최종적으로 완성되었다(Fig. 8). 최 종 의치를 시적한 후 압박지시연고(Pressure indicating paste; Mizzy, Myerstown, PA, USA)를 이용해 압박부를 삭제하고 심 미성, 교합, 발음 및 연하 등을 확인하였다. 의치 장착 후 24 시간 이내 내원을 지시하여 과도한 압박 및 통증 부위를 조절하였다. 


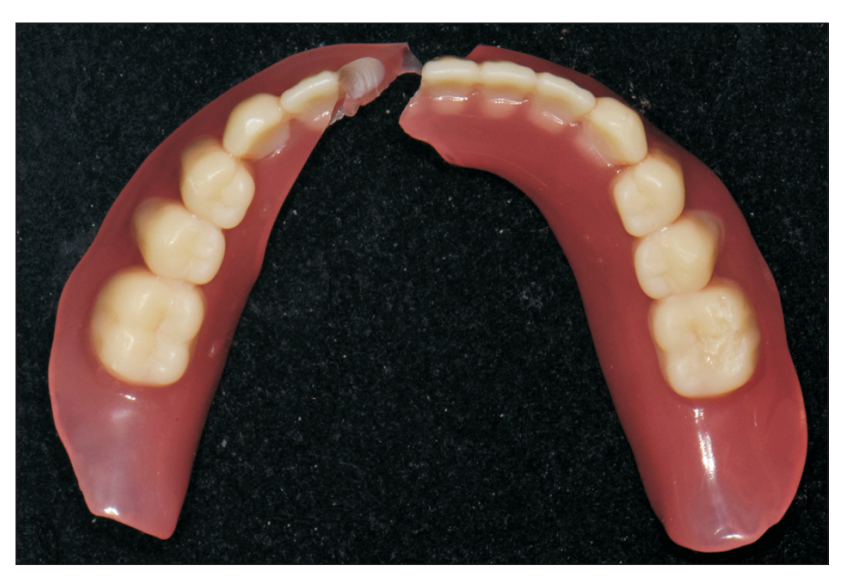

Fig. 9. Fracture of the mandibular denture.

정기검진에서 환자의 양호한 교합과 조직상태를 확인하였고 의 치의 위생관리가 잘 되고 있음을 관찰할 수 있었다. 환자는 의치 의 심미성, 유지, 발음, 저작에 대해 전반적으로 높은 만족도를 보였다. 최종 의치 제작 후 3개월 후에 하악 의치가 파절(Fig. 9) 되어 내원하였는데 절단면이 깨끗하여 순간접착제(Loctite 401; Henkel, Rocky Hill, CT, USA)로 파절된 의치를 접착시키고 알루왁스(Aluwax; Aluwax Dental Products, Allendale, MI, USA)로 중심위를 채득한 후 내면에 실리콘 인상재(Honigum Light body; DMG, Hamburg, Germany)를 도포하여 폐구 상 태에서 wash impression 채득하여 기공소에 전달하고 일주일 후 하악 최종 의치를 장착하였다. 기존 의치 데이터를 이용하여 손쉽게 빠른 의치의 제작이 가능하였고 기존 의치와 동일한 새 로운 의치를 제작함으로써 환자가 느끼는 조직점막의 편안함이 증대되어 만족도 높은 의치의 제작이 가능하였다.

\section{Discussion}

$3 \mathrm{D}$ 프린팅을 이용한 의치의 제작은 전통적인 총의치 기공 시 발생할 수 있는 열중합 레진에 의한 기공오차를 감소시키고 최 소한의 내원 횟수만으로 의치 제작이 가능하며 의치의 파절 및 분실 시에도 저장된 데이터를 재활용하여 새로운 의치를 빠르 고 쉽게 제작할 수 있다. 하지만 적은 횟수의 내원만으로 총의치 를 제작하기 위해서는 각 단계마다 최대한 많은 정보를 얻고 각 단계마다 면밀한 임상적 관찰이 이뤄지도록 하여 환자의 내원 횟수가 증가하지 않는 노력이 필요하다. 본 증례에서는 시적의 치 장착 시 의치 내면의 적합도가 약간 떨어지고 양측성 균형교 합 형성이 부족하여 시적의치 상에서 wash impression을 채득 하고 교합조정을 통해 최종의치의 제작에 반영하도록 하였다. 최종의치는 의치의 적합도, 유지력 면에서 양호한 결과를 보였 지만 모델링 컴파운드를 사용하지 않아 변연이 다소 얇고 짧게
제작되는 경향이 있었다. 코잔에서 제공하는 트레이를 이용한 고딕아치 트레이싱은 첫 내원 시 인상채득과 악간관계를 기록 할 수 있다는 장점이 있었지만 하악 트레이에 삽입되는 묘기침 의 각도가 제한적이기 때문에 상악의 묘기판과 직각이 되게 형 성하기 어려운 경우 정확한 중심위의 재현이 어려울 것으로 보 인다. 또한, 정확한 교합관계 형성을 위해 후방부의 접촉이 발생 하지 않도록 트레이 상부의 잉여 인상재를 확실히 제거해야 하 며 코잔 기공소 측의 소프트웨어 의한 인공치 배열과 교합은 악 관절의 복잡한 운동을 재현하는데 무리가 있다. 치은색과 치은 색상 모두를 선택할 수 있어 심미성 면에서 환자 선택이 폭이 넓 어지나 메탈프레임의 삽입이 불가능하여 의치 종류의 폭이 제 한적이다. 건강보험 총의치를 제작하는 경우 전통적인 총의치 제작 방식을 따라야 하는 제약이 존재한다. 하지만 전통적인 방 법보다 악간관계 채득 시 트레이 접촉부위를 조정하거나 시적 의치 장착 시 교합조정에 소요되는 시간이 증가하였지만, 내원 횟수 및 전체적인 진료 소요 시간은 감소되는 이점이 있었다. 또 한, 교합이 부적절할 경우 시적의치 상에서 교합면을 삭제 후 바 이트 인상을 채득할 수 있고 의치 내면의 적합성이 부족할시 시 적의치의 내면을 삭제 후 wash impression을 채득하며 최종의 치에 수정사항을 반영할 수 있다. 전통적인 의치에서 발견되는 열중합 레진의 기공상 수축 오차 없이 $3 \mathrm{D}$ 프린팅으로 제작되어 의치의 내면 적합도가 향상되었다. 최종 의치 장착 후 3 개월째 에 발생한 하악 의치 파절은 $3 \mathrm{D}$ 프린팅 의치상이 열중합 의치상 에 비해 굴곡강도가 낮아 파절에 더 취약하기 때문인 것으로 보 인다[5]. 또한, 본 증례에서는 발견되지 않았지만 3D 프린팅 의 치의 인공치는 의치상과 인공치 간의 낮은 접착강도에 의해 쉽 게 탈락할 가능성이 있어 보완할 필요가 있을 것으로 보인다[6].

\section{Conflicts of Interest}

The authors declare that they have no competing interests.

\section{ORCID}

\author{
Yina Yun \\ https://orcid.org/0000-0001-8443-4524 \\ Minhyuk Park \\ https://orcid.org/0000-0002-4699-2506 \\ Sangwon Park \\ https://orcid.org/0000-0002-9376-9104 \\ Chan Park \\ https://orcid.org/0000-0001-5729-5127
}


Woohyung Jang

https://orcid.org/0000-0001-8077-6877

Seon-Ki Lee

https://orcid.org/0000-0001-9590-9409

\section{References}

1. Oberoi G, Nitsch S, Edelmayer M, Janjić K, Müller AS, Agis H. 3D printing-encompassing the facets of dentistry. Front Bioeng Biotechnol 2018;6:172. doi: 10.3389/ fbioe.2018.00172.

2. Zarb GA, Bolender CL. Prosthodontic treatment for edentulous patients. 12th ed. St. Louis: Mosby; 2004;190-207.

3. Ngo TD, Kashani A, Imbalzano G, Nguyen KTQ, Hui D. Additive manufacturing (3D printing): a re- view of materials, methods, applications and challenges. Compos B Eng 2018;143:172-196. doi: 10.1016/ j.compositesb.2018.02.012.

4. Bidra AS, Taylor TD, Agar JR. Computer-aided technology for fabricating complete dentures: systematic review of historical background, current status, and future perspectives. J Prosthet Dent 2013;109:361-366. doi: 10.1016/ S0022-3913(13)60318-2.

5. Prpić V, Schauperl Z, Ćatić A, Dulčić N, Čimić S. Comparison of mechanical properties of 3D-printed, CAD/CAM, and conventional denture base materials. J Prosthodont 2020;29:524-528. doi: 10.1111/jopr.13175.

6. Choi JJE, Uy CE, Plaksina P, Ramani RS, Ganjigatti R, Waddell JN. Bond strength of denture teeth to heat-cured, CAD/CAM and 3D printed denture acrylics. J Prosthodont 2020;29:415-421. doi: 10.1111/jopr.13125. 